\title{
Self-adjustable glasses in the developing world
}

This article was published in the following Dove Press journal:

Clinical Ophthalmology

17 February 2014

Number of times this article has been viewed

\author{
Venkata S Murthy \\ Gudlavalleti' \\ Komal Preet Allagh' \\ Aashrai SV Gudlavalleti ${ }^{2}$ \\ 'Indian Institute of Public Health, \\ Public Health Foundation of India, \\ Hyderabad, ${ }^{2}$ Centre for Chronic \\ Disease Control, Public Health \\ Foundation of India, New Delhi, India
}

Correspondence: Venkata S Murthy Gudlavalleti

Director, Indian Institute of Public Health, Public Health Foundation of India, ANV Arcade, I Amar Cooperative Society, Kavuri Hills, Madhapur, Hyderabad, India 500033

Email gvsmurthy1956@gmail.com
Abstract: Uncorrected refractive errors are the single largest cause of visual impairment globally. Refractive errors are an avoidable cause of visual impairment that are easily correctable. Provision of spectacles is a cost-effective measure. Unfortunately, this simple solution becomes a public health challenge in low- and middle-income countries because of the paucity of human resources for refraction and optical services, lack of access to refraction services in rural areas, and the cost of spectacles. Low-cost approaches to provide affordable glasses in developing countries are critical. A number of approaches has been tried to surmount the challenge, including ready-made spectacles, the use of focometers and self-adjustable glasses, among other modalities. Recently, self-adjustable spectacles have been validated in studies in both children and adults in developed and developing countries. A high degree of agreement between self-adjustable spectacles and cycloplegic subjective refraction has been reported. Self-refraction has also been found to be less prone to accommodative inaccuracy compared with non-cycloplegic autorefraction. The benefits of self-adjusted spectacles include: the potential for correction of both distance and near vision, applicability for all ages, the empowerment of lay workers, the increased participation of clients, augmented awareness of the mechanism of refraction, reduced costs of optical and refraction units in low-resource settings, and a relative reduction in costs for refraction services. Concerns requiring attention include a need for the improved cosmetic appearance of the currently available self-adjustable spectacles, an increased range of correction (currently -6 to +6 diopters), compliance with international standards, quality and affordability, and the likely impact on health systems. Self-adjustable spectacles show poor agreement with conventional refraction methods for high myopia and are unable to correct astigmatism. A limitation of the fluid-filled adjustable spectacles (AdSpecs, Adaptive Eyecare Ltd, Oxford, UK) is that once the spectacles are self-adjusted and the power fixed, they become unalterable, just like conventional spectacles. Therefore, they will need to be changed as refractive power changes over time. Current costs of adjustable spectacles are high in developing countries and therefore not affordable to a large segment of the population. Self-adjustable spectacles have potential for "upscaling" if some of the concerns raised are addressed satisfactorily.

Keywords: developing countries, eye disease, refractive error, spectacles

\section{Introduction}

The World Health Organization estimated that 153 million people were visually impaired due to refractive errors in 2004. ${ }^{1}$ The major causes of visual impairment are uncorrected refractive errors (UREs; 43\%) and cataract (33\%). ${ }^{2}$ Studies have also observed that globally nearly 3,000 million people have some degree of refractive error, of whom 703 million suffer from UREs either for distance or near vision. ${ }^{3}$ Some projections have estimated the global presbyopia burden to be as high as 1.04 billion and that 
517 million of these had no available correction (ie, they did not have appropriate spectacles). ${ }^{4}$ Additionally, Fricke et al estimated that as at 2007, the loss in global gross domestic product due to UREs was around US\$202,000 million annually, while the cost of providing refraction services globally was US\$20,000 million. ${ }^{3}$ Refractive errors accounted for $26.5 \%$ of healthy years of life lost due to disability over the period 1990-2010. ${ }^{5}$ UREs have been shown to be the single largest contributor to the global burden of eye diseases. ${ }^{6}$ It has also been documented that UREs have an adverse impact on the quality of life of individuals in all parts of the globe. ${ }^{7}$ The impact of UREs is bi-dimensional, as poverty affects affordability and correction, while at the same time, the lack of correction of refractive errors can affect working capacity and productivity and therefore result in poverty. ${ }^{8}$

The impact of vision impairment due to UREs affects all levels of society. At the individual level, UREs can affect a person's educational attainment, employment, independent living, and quality of life. For example, among children, the leading and most easily remedied cause of poor vision is refractive errors. ${ }^{9}$ If uncorrected, refractive errors can greatly affect children's future because poor vision is a major barrier to achieving a sustainable, educationally healthy, school environment in many regions of the world. ${ }^{9}$ Thus, UREs pose a significant barrier to Education for All and to the attainment of the Millennium Development Goals. ${ }^{10,11}$ Recent evidence also shows that productivity and functionality among adults with myopia can also be improved if adequate correction is provided, improving participation in activities of daily living and visual functioning. ${ }^{12,13}$

\section{Barriers to the correction of refractive errors in low- and middle- income countries}

Studies show that more than $90 \%$ of the burden of eye disease occurs in low- and middle-income countries. ${ }^{6}$ These are also the countries in which access to refraction services and the availability of spectacles are poor. Even though the majority of refractive errors is easily treatable, they remain an unresolved public health problem due to the lack of skilled human resources, the cost of spectacles, and logistics issues in the supply chain for providing spectacles to those populations that need them. In low- and middle-income countries, one of the major challenges is the paucity of skilled human resources for refraction testing and treating. ${ }^{14,15}$ The lack of trained ophthalmic support personnel such as assistants and technicians in developing countries has increased the workload of highly skilled ophthalmologists. ${ }^{14}$ The limited availability of appropriate spectacle correction is also another challenge in redressing the existing situation in most low- and middle-income countries. ${ }^{16}$

Cost is a major barrier to the universal availability of spectacles. Studies have shown that willingness to pay for spectacles is low, as was observed in East Timor, where nearly half the people were not willing to pay more than US\$1 for a pair of spectacles. ${ }^{17}$ Cost of spectacles and affordability have been highlighted as important barriers to spectacle use in India, ${ }^{18}$ Zanzibar, ${ }^{19}$ the People's Republic of China, ${ }^{20}$ and in many other countries.

All these factors lead to low spectacle coverage rates which refers to the proportion of people wearing spectacles as the denominator of people needing spectacles computed from population-based surveys - as has been observed in many studies in low- and middle-income countries. For instance, in Andhra Pradesh, India, the spectacle coverage rate was found to be $29 \%,{ }^{21}$ while it was found to be $15.1 \%$ in Pakistan, ${ }^{22}$ $25.2 \%$ in Bangladesh, ${ }^{23}$ and $3.4 \%$ in Nigeria. ${ }^{24}$

It is critical that cost-effective strategies be developed to provide spectacles in low- and middle-income countries. In countries where the availability of human resources and cost of spectacles are of concern, any strategy that can address these barriers could go a long way toward improving refraction services and spectacle use.

\section{Strategies for reducing the cost of spectacle delivery}

The cost of spectacles is partly driven by the need for customizing lenses based on differing spherical and cylindrical powers in each eye. ${ }^{25}$ This entails higher costs, as human resources and equipment for cutting and fitting are required. Various methods have been tried to reduce costs. One of the commonest is the use of ready-made spectacles (RSMs). RSMs reduce costs as they are produced in bulk with the same refractive power in both eyes, common frames, and limited diopter steps. ${ }^{25}$ A number of studies have documented findings on the use of RSMs in India, ${ }^{26}$ Australia, ${ }^{27}$ and the People's Republic of China. ${ }^{28}$ In the People's Republic of China, where RSMs were compared with customized spectacles in school children, though RSMs achieved poorer visual acuity, the acceptance rates were similar. ${ }^{28}$ The study in Australia, which considered adult populations, concluded that $20 \%$ of the need for spectacles could be easily met by RSMs ${ }^{27}$ but the remaining $80 \%$ of need would have to be met by customized spectacles, which would require specialist human resources. However, the study from India observed that the need for customized spectacles was not as high as 
that reported in the Australian study. ${ }^{26}$ These findings suggest that RSMs may be a solution to the issue but will usually need the backup support of refraction services.

Another approach that has been experimented with is the "focometer", $16,29,30$ which is a monocular, self-adjustable telescopic refractive device that allows an individual's refractive power to be read off a linear diopter scale. Subjects rotate the focometer until the best focus is obtained. This is then used to prescribe the required power for the spectacles. ${ }^{30}$ However, the focometer can only measure refractive error and cannot replace optical dispensing, unlike RSMs.

A promising alternative approach is self-adjusting spectacles, discussed in detail following.

\section{Self-adjustable spectacles}

It has been claimed that self-adjustable spectacles offer promise as a novel approach to vision correction in regions where there is a paucity of trained personnel.., 31 Compared with the focometer, self-adjustable spectacles not only allow the user to adjust the power of each lens independently to achieve client satisfaction, but a pair can also worn as a corrective device. ${ }^{9,31}$ This self-refraction technique is a potential solution to the shortfall of eye-care professionals in developing countries, as it enables an individual to self-adjust the lens power to arrive at an adequate level of vision. These novel self-refracting spectacles have been shown to achieve good vision both in adults ${ }^{16,31}$ and children. ${ }^{9,32}$

The variable-focus lens spectacles exist in two categories, one employing fluid-filled lenses wherein fluid is injected or removed into a bladder-like sac to change the power of the lens system (AdSpecs; Adaptive Eyecare Ltd, Oxford, UK), while the other uses Alvarez optics, employing two lens systems that move relative to each other in a spectacle frame, causing changes in lens power. ${ }^{33}$ In recent years, there has been interest in using Alvarez' lenses as adjustable-focus spectacle lenses in developing countries. ${ }^{33}$ "Universal spectacles" (U-Specs; [VU University Medical Centre, Amsterdam, the Netherlands) are based on the Alvarez principle to achieve the desired refractive power and are adjustable using a simple tool, ${ }^{34}$ while the adjustable fluidfilled lenses in the self-refracting spectacles (AdSpecs) allow power of the lenses to be changed to correspond to spherical equivalent (SE). ${ }^{16,31}$

With AdSpecs, the fluid-filled lenses consist of two membranes, $23 \mu \mathrm{m}$ thick, sealed at a circular perimeter of diameter $42 \mathrm{~mm}$ and secured by a frame. ${ }^{31,32}$ The front face of each deformable lens is protected by a rigid plastic cover, and the optical power of the lens is determined by the curvature of its surfaces, which is controlled by varying the volume of the liquid in the lens. ${ }^{31,32}$ Two user-controlled pumps, marked with a scale in diopters and capable of withdrawing or returning fluid to the two lens chambers independently, are attached to the sides of the spectacle frames. ${ }^{31,32}$ The lens is sealed and the adjustment mechanism removed after the desired power is obtained. ${ }^{31,32}$ Due to this procedure, it is essential that a trained facilitator, if not an optometrist or ophthalmologist, is present to guide the process in low- and middle-income countries, as these countries are usually characterized by low levels of literacy.

U-Specs consist of two lenses that slide over each other to achieve the desired refractive power. Thus, there is no need for fluid to be used in the spectacles. ${ }^{34} \mathrm{~A}$ dial on the spectacles can be adjusted to provide refractive correction in the range of -6 to +3 diopters (D). ${ }^{35}$

\section{Validation of self-adjustable spectacles in school-aged children}

Different types of self-adjustable spectacles have been validated in studies both in the developed and developing world (Table 1). Self-adjustable spectacles (liquid filled) have been tried in school-aged children in the $\mathrm{USA}^{36}$ and the People's Republic of China, ${ }^{9,32}$ and in older populations in the USA, ${ }^{16}$ South Africa, ${ }^{31,37}$ Ghana, ${ }^{31,37}$ Malawi, ${ }^{31}$ Nepal, ${ }^{31}$ and Nicaragua. ${ }^{16}$ Cycloplegic refraction was considered the gold standard in the studies in the $\mathrm{USA}^{36}$ and the People's Republic of China., ${ }^{9,32}$ It was observed that nearly $92 \%$ of the children in Boston, USA; ${ }^{36} 85 \%$ in Guangzhou, People's Republic of China; ${ }^{9}$ and nearly 97\% in Chaoshan, People's Republic of China, ${ }^{32}$ were able to attain a vision of 6.0/7.5. Agreement between self-adjustment and subjective cycloplegic refraction was very good in all these studies. The US study ${ }^{36}$ showed that the type of refractive error affected agreement, as there was no agreement in children with any degree of astigmatism. Agreement was found to be poorer in the presence of high myopia/hyperopia or in the presence of astigmatism in Chaoshan, People's Republic of China. ${ }^{9}$ Similar findings were also observed in Guangzhou, People's Republic of China. ${ }^{32}$

Comparison of cycloplegic subjective refraction with selfrefraction in Chaoshan, People's Republic of China, showed that there was no significant difference between subjective refraction and self-refraction $(P=0.256)$, with a median value of $0.00 \mathrm{D}$ and $95 \%$ of values between -0.750 and $0.875 .{ }^{9}$ In Guangzhou, People's Republic of China, the difference between cycloplegic subjective refraction and self-refraction again did not differ significantly $(P=0.33 ;-0.009 \mathrm{D}){ }^{32}$ 


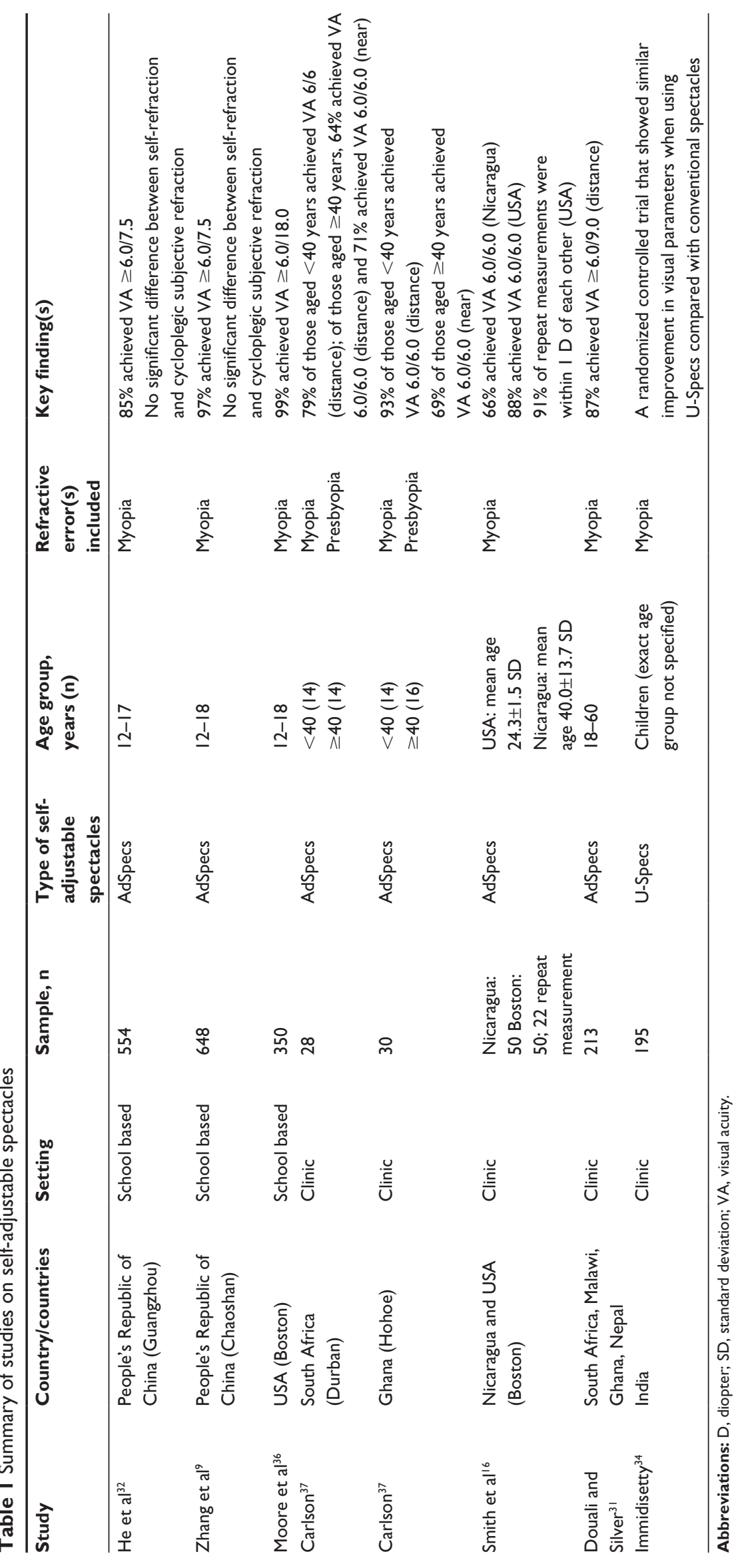


In both studies from the People's Republic of China, the mean difference between cycloplegic subjective refraction and noncycloplegic autorefraction was significant. ${ }^{9,32}$ It was therefore concluded that self-refraction was less prone to accommodative inaccuracy than non-cycloplegic autorefraction.

A recent randomized controlled trial of RSMs compared with customized spectacles observed that among school children at 1-month follow-up, there were no differences between the two groups for simple myopic correction. ${ }^{36}$

Both RSMs and self-adjustable spectacles can be useful in countries/regions in which trained human resources for eye care are scarce. They therefore offer an alternative approach to the provision of affordable glasses. Since self-adjustable spectacles need clients to actively maneuver the attachments on the frame to select the best vision, there may be a better sense of ownership, which may improve compliance and continued usage of the spectacles.

\section{Validation of self-adjustable spectacles in adults}

Compared with the large community interventions that have approached the use of liquid-filled self-adjustable spectacles in children, very few studies have looked at older populations and those that have mostly involved small numbers of participants in office/clinic settings. A total of 213 persons aged 18-60 years were recruited to a study in Ghana, Nepal, Malawi, and South Africa. ${ }^{31}$

Another study, which included 50 subjects from Boston, USA (mean age $24.3 \pm 1.5$ years) and 50 from Nicaragua (mean age $40.0 \pm 13.7$ years), compared adjustable spectacles (AdSpecs) and a focometer with subjective refraction. ${ }^{16}$ Subjects were only recruited if they had no obvious or known ocular pathology and/or amblyopia. In Nicaragua, subjects were recruited from those attending an eye clinic, while in the USA, subjects were invited to participate by email sent to a student body. In the USA, 22 subjects also had a repeat measurement with the AdSpecs at a later date. ${ }^{16}$ Participants' SE and best-corrected visual acuity were determined during the study, and subjective refraction for the comparison was measured by a trained optometrist. The measurements were performed in a random fashion to eliminate bias. The measurements for the alternate methods were performed by a layperson.

It was observed that, on the average, the measure of refractive error with self-adjustable spectacles was not significantly different from that of subjective refraction, but in Boston there was a significant difference between the measurement of refractive error made with the focometer and that of subjective refraction. ${ }^{16}$ In Boston, it was also observed that the difference between the SE measured by the adjustable spectacles and focometer compared with subjective refraction became larger as the degree of myopia increased. The adjustable spectacles overestimated myopia compared with subjective refraction, especially among those with a higher degree of myopia. The authors concluded that in approximately $5 \%$ of the high-myope population, selfassessment of refractive error with adjustable spectacles would differ from measurements obtained by subjective refraction by at least 1.7 D. ${ }^{16}$ In Nicaragua, where there were few myopes, the differences between adjustable spectacles and subjective refraction increased when the degree of hyperopia was high. ${ }^{16}$ In this Nicaraguan population, $88 \%$ of the adjustable-spectacle readings were within 1 $\mathrm{D}$ of the corresponding measurement obtained by subjective refraction. ${ }^{16}$ In the Boston arm, $88 \%$ of subjects with adjustable spectacles, compared with $98 \%$ measured by subjective refraction, were able to achieve a vision of $6 / 6$. In Nicaragua, the corresponding proportions were $78 \%$ for subjective refraction and $66 \%$ for adjustable spectacles. ${ }^{16}$ Repeat measurements with adjustable spectacles showed that $91 \%$ of repeat measurements were within $1 \mathrm{D}$ of the first measurement, showing that repeatability accuracy is high with adjustable spectacles. ${ }^{16}$

AdSpecs are now being used in country programs in Ghana ${ }^{14}$ and Rwanda. ${ }^{38}$ Over 30,000 pairs of these spectacles have been reported to have been distributed in Ghana in collaboration with the Ghanaian Ministry of Education. It has been reported after an initial evaluation that $70 \%$ of people have corrected their vision at least as well as, if not better than, an optometrist. ${ }^{14}$ In Rwanda, it has been reported that nurses are being trained to do vision assessments and vision correction using adjustable spectacles to redress the shortage of optometrists in the country. ${ }^{38}$

A randomized controlled user trial of U-Specs was recently undertaken at three locations in India. ${ }^{34} \mathrm{~A}$ total of 195 participants were enrolled at three centers and U-Specs were compared with conventional spectacles. It was observed that the visual improvement parameters were similar between the groups. ${ }^{34}$

\section{Benefits of self-adjustable spectacles}

The available evidence from the few studies conducted with self-adjustable spectacles shows that this novel approach has some potential benefits, especially in poorly resourced settings. Some of the reported benefits are discussed following. 
First, self-adjustable spectacles can be used to correct both distance and near vision problems. ${ }^{34}$ The spectacles have been validated for use for distance vision among adults in the USA and Nicaragua, ${ }^{16}$ Ghana, Malawi, Nepal, and India, ${ }^{31}$ and among children in the People's Republic of China. ${ }^{9,32}$ Only one study in Ghana looked at the benefit of adjustable spectacles for near vision, although this study only had a small group of 16 participants aged $40+$ years. ${ }^{37}$ The study found that $6 / 6$ vision was achieved by eleven of the 16 participants $(78.6 \%)$ with self-adjustable silicone liquid-filled spectacles. ${ }^{37}$

Self-adjustable refraction also brings in the element of client participation, and this may result in better compliance rates than what has been generally reported. This may also help in increasing awareness of how refractive errors are caused and how they can be corrected.

Another benefit of self-adjustable spectacles is that they can be used by clients of all ages - children as well as adults, as has been demonstrated by studies with adults in the USA and Nicaragua; ${ }^{16}$ Ghana, Malawi, Nepal, and India; ${ }^{31}$ and among children in the People's Republic of China., ${ }^{9,32}$

Further, empowering lay workers or nurses with skills to monitor self-adjustment will reduce the workload of eyecare providers in low- and middle-income countries, many of which are grappling with a human-resource crunch in eye care. The technology can also be used as a screening protocol for refractive errors and be embedded in eye-care programs.

It has been stated that self-adjustable spectacles can reduce the costs involved in delivering refraction services by curtailing expenditure for human resources and for developing the infrastructure for optical units for cutting and grinding. ${ }^{31}$ This needs more scrutiny, as trained human resources and infrastructure will be needed for both cylindrical correction and high myopia, which have been flagged by many studies as areas of concern with regard to poor results with self-adjustable spectacles. ${ }^{9,16,28,32}$

Another potential advantage reported is that the power of some self-adjustable lenses can be modified, which can be helpful in addressing the problem of outdated and inaccurate spectacles. This is a problem in many developing countries where people continue to use broken/damaged/inaccurate spectacles because they cannot afford replacements and/or they have poor access to refraction services. ${ }^{31}$ Very little specialized equipment is needed for the fitting of self-adjustable spectacles, therefore the technology can reduce costs. Among the currently available self-adjustable spectacles, only those using Alvarez optics (U-Specs) allow for the refractive power to be continually changed based on visual need, so it may be possible to use these for distance, intermediate, and near correction at the same time.

An alternative approach that combines self-adjustable spectacles as the diagnostic element of a refraction service coupled with provision of an array of RMSs for dispensing has been mooted by some professionals. ${ }^{39}$ This interesting approach may be feasible for adoption in rural and remote areas in some countries but would need to be closely supervised by trained refraction service managers.

\section{Concerns regarding self-adjustable spectacles}

There are also a number of concerns about self-adjustable spectacles, some of which are considered following.

First, compliance with spectacles is dependent both on cost as well as the cosmetic appearance of the glasses. Peer pressure and "teasing" are barriers to spectacle wear in developing countries that are commonly expressed. ${ }^{40-42}$ The acceptability of the glasses by the community in terms of the cosmetic appearance of self-adjustable spectacles has not yet been studied. ${ }^{32,39}$ It is therefore important to obtain and apply evidence on this, as this will have a long-term impact on the sustainability of the approach.

Further, studies have shown that children with greater levels of spherical and cylindrical refractive errors are at risk of inaccurate self-refraction. In the case of high-level spherical refractive errors, inaccurate self-refraction can occur because self-adjustable spectacles are incapable of correcting astigmatism, while with high-level cylindrical refractive errors, this can occur because the range of correction with this device is limited to -6 to +6 D. ${ }^{9,32}$ Recently, a study has reported successful results for all types of refractive errors including astigmatism with "Smart Glasses" (S-Glasses; [Treacy MP, Dublin, Ireland]), which are a set of preformed lenses that fit frames with standardized apertures supported by an autorefractometer operated by a nonspecialist health worker. ${ }^{43}$ Due to the availability of such alternatives, self-adjustable spectacle technology needs to be improved to meet the needs of a wide range of refractive errors if the load on existing eye-care systems is to be reduced.

Another concern about self-adjustable spectacles is that their cost is relatively high for most low- and middleincome countries. It is likely that the principle of economies of scale may reduce costs significantly in the future, but, at present, the spectacles may not be affordable to most poor communities. Cost-effectiveness analysis would need to compare the costs of the spectacles and the logistics 
(including human resources) of the self-adjustable spectacles with other alternative approaches including conventional refraction and optical systems, RSMs, and other alternatives like focometers, against a common parameter of effectiveness - like level of vision correction and comfort in the short term, and spectacle utilization and adverse effects, if any, in the long term. If policy makers are to be convinced, the cost-effectiveness ratios will have to be very high compared with conventional methods.

The safety and long-term accuracy of self-adjustable spectacles have not been studied in any of the studies, to date, and one study highlights this concern. ${ }^{32}$ If the spectacles are to be used more widely, evidence to support the safety and long-term accuracy is a must.

In addition, the long-term acceptability of self-adjustable spectacles needs to be studied, as compliance rates/spectacleusage rates are known to diminish over time, once the novelty wears off. A study in Thailand reported that spectacle utilization rates with RSMs were significantly higher at 6 months following provision than at 12 months after provision. ${ }^{44}$ Adolescents and young adults are conscious of how they look and how their peer group reacts to them; therefore, before self-adjustable spectacles are advocated, studies on acceptance of the product by its potential clients are essential.

If adjustable spectacles are to help reduce the global burden of UREs, they need to meet International Organization for Standardization (ISO) standards and be comparable to conventional RSMs and custom-made spectacles in terms of affordability, quality, and deliverability through an eye examination conducted by a trained person. ${ }^{45}$ The International Agency for the Prevention of Blindness has stated that affordability and quality benchmarks are more likely to be achieved by the Alvarez lens system in the future. ${ }^{45}$

The International Agency for the Prevention of Blindness is also of the opinion that adjustable spectacles have no role in the provision of refractive care to children due to their inability to control accommodation, so this is another concern with these glasses. ${ }^{45}$

Another concern is that although it has been stated that self-adjustable spectacles are useful in regions/countries in which there is a paucity of eye-care human resources, it is possible that governments/policy makers may use this argument to say that training programs or the creation of cadres for refraction or eye care are not necessary and therefore withhold funding for developing the requisite human resources and infrastructures for eye care. This would undermine the philosophy of the global initiative VISION 2020: The Right to Sight, ${ }^{45}$ which envisaged that countries would invest resources in developing human resources and infrastructure for eye care.

Finally, all the studies conducted with self-adjustable glasses have only reported outcomes based on visual acuity. It is also important to evaluate other parameters like contrast sensitivity, stereopsis, and glare, since self-adjustable glasses are thick, so additional research is required in these areas.

\section{Future scope for self-refraction}

Self-adjustable spectacles have the capacity to redress the need for refraction and optical services in countries that are challenged with inadequate human resources for refraction. Though they are more affordable than conventional spectacles, the costs are still high for many low- and middleincome countries. Design aspects also need to be considered and efforts should be made to improve the cosmetic appearance to attract clients, especially young adults and children. Studies have shown that self-adjustable spectacles have the dual benefit of being used both as a refraction technique as well as a prescription, ${ }^{16,32}$ unlike focometers and off-the-shelf RSMs, which serve only a unitary purpose.

The currently available adjustable spectacles have a limited range of power ( -6 to $+6 \mathrm{D}),{ }^{9}$ and innovation is needed to enhance this range using the principle of self-adjustment. This is critically important, as it has been demonstrated in the studies undertaken to date that agreement with subjective refraction is poorer both for high myopia and high hyperopia. Improvement is also needed to correct astigmatism to make self-adjustable lenses an acceptable comprehensive product in the future.

It is essential that refraction services be considered as part of a comprehensive eye-care system. This means that capacity has to be built in the country/region to recognize eye problems and refer individuals to eye specialists when spectacles do not help improve vision. Such screening, case-detection, and management programs will need trained human resources. Moreover, there should be a system in place to tackle the potential complications associated with spectacles ${ }^{45}$ Considering all aspects, the best option, at present, would be to integrate self-adjustable spectacles of proven credentials into the eye-/health-care system of a country/ region so that the service is supported by an appropriate referral mechanism for other eye problems needing the attention of skilled eye-care professionals.

\section{Disclosure}

The authors declare no conflicts of interest in this work. 


\section{References}

1. Resnikoff S, Pascolini D, Mariotti SP, Pokharel GP. Global magnitude of visual impairment caused by uncorrected refractive errors in 2004. Bull World Health Organ. 2008;86(1):1-80.

2. Pascolini D, Mariotti SP. Global estimates of visual impairment: 2010. Br J Ophthalmol. 2012;96(5):614-618.

3. Fricke TR, Holden BA, Wilson DA, et al. Global cost of correcting visual impairment from uncorrected refractive error. Bull World Health Organ. 2012;90(10):713-792.

4. Holden BA, Fricke TR, Ho M, et al. Global vision impairment due to uncorrected presbyopia. Arch Ophthalmol. 2008;126(12): $1731-1739$.

5. Vos T, Flaxman AD, Naghavi M, et al. Years lived with disability (YLDs) for 1160 sequelae of 289 diseases and injuries 1990-2010: a systematic analysis for the Global Burden of Disease Study 2010. Lancet. 2012;380(9859):2163-2196.

6. Ono K, Hiratsuka Y, Murakami A. Global inequality in eye health: country-level analysis from the Global Burden of Disease Study. Am J Public Health. 2010;100(9):1784-1788.

7. Naidoo KS, Ravilla D. Delivering refractive error services: primary eye care centres and outreach. Community Eye Health. 2007;20(63): $42-44$.

8. Naidoo KS, Jaggernath J. Uncorrected refractive errors. Indian J Ophthalmol. 2012;60(5):432-437.

9. Zhang M, Zhang R, He M, et al. Self correction of refractive error among young people in rural China: results of cross sectional investigation. BMJ. 2011;343:d4767.

10. UNESCO [homepage on the Internet]. Education for All. Available from: http://www.unesco.org/new/en/education/themes/leading-theinternational-agenda/education-for-all/ Millennium Development Goals. Accessed February 5, 2014.

11. United Nations [homepage on the Internet]. Millennium Development Goals. Available from: http://www.un.org/millenniumgoals/. Accessed February 5, 2014.

12. Lamoureux EL, Saw SM, Thumboo J, et al. The impact of corrected and uncorrected refractive error on visual functioning: the Singapore Malay Eye Study. Invest Ophthalmol Vis Sci. 2009;50(6): 2614-2620

13. McClure TM, Choi D, Wooten K, Nield C, Becker TM, Mansberger SL. The impact of eyeglasses on vision-related quality of life in American Indian/Alaska Natives. Am J Ophthalmol. 2011;151(1):175-182.

14. Karnani A, Garrette B, Kassalow J, Lee M. Better vision for the poor. Stanford Social Innovation Review. Spring 2011. Available from: http:// www.ssireview.org/articles/entry/better_vision_for_the_poor. Accessed October 10, 2013.

15. Nkumbe H. Situation analysis of human resources for eye care in the North West Province of Cameroon. Community Eye Health. 2007;20(61):13

16. Smith K, Weissberg E, Travison TG. Alternative Methods of Refraction: A Comparison of Three Techniques. Optom Vis Sci. 2010;87(3): E176-E182.

17. Ramke J, du Toit R, Palagyi A, Brian G, Naduvilath T. Correction of refractive error and presbyopia in Timor-Leste. Br J Ophthalmol. 2007;91(7):860-866.

18. Marmamula S, Keefe JE, Raman U, Rao GN. Population-based crosssectional study of barriers to utilisation of refraction services in South India: Rapid Assessment of Refractive Errors (RARE) Study. BMJ Open. 2011;1(1):e000172.

19. Laviers HR, Omar F, Jecha H, Kassim G, Gilbert C. Presbyopic spectacle coverage, willingness to pay for near correction, and the impact of correcting uncorrected presbyopia in adults in Zanzibar, East Africa. Invest Ophthalmol Vis Sci. 2010;51(2):1234-1241.

20. Li L, Song Y, Liu X, et al. Spectacle acceptance among secondary school students in rural China: the Xichang Pediatric Refractive Error Study (X-PRES) - report 5. Invest Ophthalmol Vis Sci. 2008;49(7): 2895-2902.
21. Marmamula S, Keeffe JE, Rao GN. Uncorrected refractive errors, presbyopia and spectacle coverage: results from a rapid assessment of refractive error survey. Ophthalmic Epidemiol. 2009;16(5): 269-274.

22. Shah SP, Jadoon MZ, Dineen B, et al. Refractive errors in the adult pakistani population: the national blindness and visual impairment survey. Ophthalmic Epidemiol. 2008;15(3):183-190.

23. Bourne RR, Dineen BP, Huq DM, Ali SM, Johnson GJ. Correction of refractive error in the adult population of Bangladesh: meeting the unmet need. Invest Ophthalmol Vis Sci. 2004;45(2):410-417.

24. Ezelum C, Razavi H, Sivasubramaniam S, et al; Nigeria National Blindness and Visual Impairment Study Group. Refractive error in Nigerian adults: prevalence, type, and spectacle coverage. Invest $O p h-$ thalmol Vis Sci. 2011;52(8):5449-5456.

25. Brady CJ, Villanti AC, Gandhi M, Friedman DS, Keay L. Visual function after correction of distance refractive error with ready-made and custom spectacles: a randomized clinical trial. Ophthalmology. 2012;119(10):2014-2020

26. Keay L, Gandhi M, Brady C, et al. A randomized clinical trial to evaluate ready-made spectacles in an adult population in India. Int J Epidemiol. 2010;39(3):877-888.

27. Maini R, Keeffe J, Weih LA, McCarty CA, Taylor HR. Correction of refractive error in the Victorian population: the feasibility of "off the shelf" spectacles. Br J Ophthalmol. 2001;85(11):1283-1286.

28. Zeng Y, Keay L, He M, et al. A randomized, clinical trial evaluating ready-made and custom spectacles delivered via a school-based screening program in China. Ophthalmology. 2009;116(10):1839-1845.

29. Berger IB, Spitzberg LA, Nnadozie J, et al. Testing the FOCOMETERA new refractometer. Optom Vis Sci. 1993;70(4):332-338.

30. Murthy G, Johnson GJ. The focometer: use in aphakic correction. Community Eye Health. 1999;12(31):43.

31. Douali MG, Silver JD. Self-optimised vision correction with adaptive spectacle lenses in developing countries. Ophthalmic Physiol Opt. 2004;24(3):234-241.

32. He M, Congdon N, MacKenzie G, Zeng Y, Silver JD, Ellwein L. The child self-refraction study results from urban Chinese children in Guangzhou. Ophthalmology. 2011;118(6):1162-1169.

33. Barbero S, Rubinstein J. Adjustable-focus lenses based on the Alvarez principle. J Opt. 2011;13:125705.

34. Immidisetty V, Ganesh S, Meshramkar S, Sudhan A, van der Heijde R. A new vision corrective device, the Universal Spectacles (U-Specs) for vision correction among children in India. Community Eye Health. 2009;22(70):S125.

35. VU University Medical Center. U-Specs [website on the Internet]. Amsterdam: VU University Medical Center; nd. Available from: http:// www.u-specs.org/?page=18054. Accessed January 7, 2014.

36. Moore B, Johnson C, Lyons S, et al. 2011. The Boston Child Self-Refraction Study. Poster presented at American Academy of Optometry 2011 conference, Boston. October 12-15, 2011. Available from: http://www. vdwoxford.org/resources/1110_aao.pdf. Accessed October 25, 2013.

37. Carlson AS. The innovative self-adjustable Adspecs ${ }^{\mathrm{TM}}$. South African Optometrist. 2005;64(1):18-25.

38. Warlich A. Adjustable glasses to improve vision of thousands in Rwanda. Borgen Magazine. nd. Available from: http://www.borgenmagazine. com/adjustable-glasses-to-improve-vision-of-thousands-in-rwanda/. Accessed November 25, 2013.

39. Keay L, Friedman DS. Correcting refractive error in low income countries. BMJ. 2011;343:d4793.

40. Ebeigbe JA, Kio F, Okafor LI. Attitude and beliefs of Nigerian undergraduates to spectacle wear. Ghana Med J. 2013;47(2):70-73.

41. Odedra N, Wedner SH, Shigongo ZS, Nyalali K, Gilbert C. Barriers to spectacle use in Tanzanian secondary school students. Ophthalmic Epidemiol. 2008;15(6):410-417.

42. Castanon Holguin AM, Congdon N, Patel N, et al. Factors associated with spectacle-wear compliance in school-aged Mexican children. Invest Ophthalmol Vis Sci. 2006;47(3):925-928. 
43. Treacy MP, Treacy MG, Dimitrov BD, Seager FE, Stamp MA, Murphy CC. A method for the prescription of inexpensive spectacles by nonspecialist healthcare workers: S-Glasses. Eye (Lond). 2013;27(4):474 479.

44. Vincent JE, Netek S, Parry A, Mladenovich D, Thein NN, Amendola PR. Reported wearing compliance of ready-made spectacles at 6 and 12 months. Optom Vis Sci. 2010;87(12):958-965.
45. International Agency for the Prevention of Blindness (IAPB). Draft Position Paper: Adjustable Spectacles. London: IAPB; 2010. Available from: http://www.iapb.org/sites/iapb.org/files/IAPB_draft_Position_ statement_on_Adjustable_Specs_6th_Mar_2010_doc.doc. Accessed December 23, 2013.

\section{Publish your work in this journal}

Clinical Ophthalmology is an international, peer-reviewed journal covering all subspecialties within ophthalmology. Key topics include: Optometry; Visual science; Pharmacology and drug therapy in eye diseases; Basic Sciences; Primary and Secondary eye care; Patien Safety and Quality of Care Improvements. This journal is indexed on

Submit your manuscript here: http://www.dovepress.com/clinical-ophthalmology-journal

\section{Dovepress}

PubMed Central and CAS, and is the official journal of The Society of Clinical Ophthalmology (SCO). The manuscript management system is completely online and includes a very quick and fair peer-review system, which is all easy to use. Visit http://www.dovepress.com/ testimonials.php to read real quotes from published authors. 